\title{
Interatividade e Motivação em Livro Digital
}

\author{
Interactivity and motivation in digital book
}

- Marcele Cassol Licht marcele.licht@gmail.com

\author{
- Berenice Santos Gonçalves \\ berenice@cce.ufsc.br
}

\begin{abstract}
The development of digital devices such as tablets allowed different ways to present content by the use of multimedia and interactive resources. In this sense, the existing interactivity in digital book has features that make it different from the printed book. So the reader will have specific interests on using a digital book. Therefore, this article performs a descriptive analysis on WWF Together interactive digital book, which starts from two axes: considers the interface interactivity and the reader's motivation. After this analysis it was possible to understand the relationship between interactivity and digital book content representation, aiming to encourage the reader's motivation.
\end{abstract}

Keywords: Design, Digital Book, Interactivity, Motivation

\section{Introdução}

A tecnologia evolui constantemente, desenvolvendo e aprimorando mecanismos para otimizar as atividades realizadas pelas pessoas. Uma vez que o design sempre esteve relacionado à tecnologia de uma época, encontra sempre novas possibilidades de atuação que ampliam os meios de criar artefatos (ROGERS; SHARP; PREECE, 2013).

Assim, o livro digital ou e-book surge em decorrência de um período de transição, em que o livro passa a ser publicado também no formato digital, além do formato impresso. Desse modo, o livro digital refere-se ao tipo de publicação em, formato eletrônico, que necessita de um dispositivo apropriado para o seu acesso. Devido aos atributos correspondentes à essa natureza de publicação, os conteúdos podem ser construídos fazendo uso de diferentes mídias. Dessa maneira, a interação do leitor com o conteúdo interativo adquire uma abordagem própria, pois, as informações podem ser apresentadas de modo dinâmico estimulando a participação do leitor (MARZANO et al. 2013).

A interação estabelecida entre o sujeito e a interface envolve uma dimensão ampla, perpassando os fatores objetivos para abranger, também, os fatores subjetivos. Por essa razão, dois níveis semânticos participam do processo de interação do sujeito com o objeto: o nível funcional e o nível emocional. Enquanto os atributos relacionados ao nível funcional são expressões do produto (atributos intrínsecos ao objeto), as respostas emocionais são inerentes do sujeito, porém, vale destacar que são provocadas pelas características percebidas a partir do objeto (QUEIROZ; CARDOSO; GONTIJO, 2009).

Assim, este artigo pretende analisar a interface de um livro digital considerando a interatividade da interface e a motivação do leitor. A primeira parte deste artigo, destina-se ao referencial teórico, abordando assuntos referentes ao livro digital. Na segunda parte, o artigo descreve o objeto de estudo, apresentando o livro digital escolhido como exemplo. Em seguida, os resultados das análises descritivas são explicitadas.

Nas análises foram adotadas as recomendações para promover a motivação em objetos educacionais, dos autores Alves e Battaiola, (2011), a fim de decompor os elementos da interface sob os aspectos indicados pelos autores. No intuito de verificar, também, o potencial de interação, foi utilizado os componentes de interatividade de Laurel (1991) apud Tori (2008). Por fim, as discussões fazem uma reflexão sobre os resultados das análises e uma relação com o potencial da interatividade para a motivação em livro digital interativo.

\section{Referencial Teórico}

A partir dos constantes avanços da tecnologia, foi possível observar o reflexo que as mudanças proporcionaram ao desenvolvimento dos artefatos. Assim, o livro passou por várias modificações, tanto em sua estrutura como também na 
forma de sua concepção (HASLAM, 2010; LÉVY, 1993). Nesse contexto, muitos componentes da configuração dos livros foram sendo alterados até seu formato digital conhecido hoje. Em vista disso, o livro digital surge como uma forma específica de publicação que possui características próprias.

Para Procópio (2010) o dispositivo digital possui propriedades que diferenciam o livro digital do impresso, como por exemplo, a possibilidade de integrar conteúdos multimídia e recursos interativos; armazenar vários exemplares em um único equipamento portátil; possuir custo inferior ao impresso e ter acesso rápido devido à aquisição pela internet.

Os formatos mais utilizados na produção dos livros digitais são o PDF, o e-pub e o aplicativo. O PDF é frequentemente utilizado como o arquivo que inclui texto e imagem, mas que pode fazer uso de elementos como hipertexto, animações e vídeos. O e-pub, possui uma estrutura própria para exibir publicações digitais podendo utilizar recursos de programação. Por fim, o formato aplicativo, permite variadas possibilidades para incluir recursos multimídia e interativos ao conteúdo, tornando a apresentação das informações mais diversificadas (PINSKY, 2013).

Os diferentes formatos de livros digitais implicam variados níveis de interatividade. Entretanto, o livro digital não deve ser visto como a simples transposição do conteúdo impresso para o digital. Devido as possibilidades de interações oferecidas aos leitores, a interatividade torna-se o diferencial mais significativo do livro digital. Essa particularidade do livro eletrônico, além de ser um incentivo à leitura de livros dessa natureza, utiliza as funcionalidades no intuito de facilitar a assimilação das informações. Sendo assim, os dois suportes possuem naturezas distintas e podem ser tratados de modo complementar (UNGARETTI; FRAGOSO, 2012).

Nesse contexto, existe a necessidade de compreender as particularidades que o meio digital proporciona, tendo em vista fazer melhor uso das potencialidades do livro digital a fim de otimizar a interação do leitor com o conteúdo.

\section{Interatividade do Livro Digital}

O desenvolvimento tecnológico dos dispositivos e sistemas digitais expandiram as possibilidades de apresentação das informações. Essa é uma das razões para a crescente complexidade na elaboração e publicação de conhecimentos. Nesse cenário, a interface é responsável por estabelecer a mediação, entre o usuário e o sistema, para que a interação seja efetiva (BONSIEPE, 2012; COELHO, 2008).

É importante salientar que o termo interação, utilizado por diversas áreas do conhecimento, evidencia a influência mútua existente entre dois ou mais fatores envolvidos em uma relação. Por outro lado, a interatividade de um sistema é atribuída à qualidade da interface. Assim, a interatividade representa o potencial de interação, ou seja, correspondente às oportunidades de atuação oferecidas ao usuário (PRIMO; CASSOL, 1999, TORI 2008).

Bonsiepe (2012) evidencia que, a forma como os conteúdos são expostos aos leitores poderá modificar a recepção e interpretação, assim como, permitir uma ação mais eficiente sobre os recursos utilizados. Em vista disso, a interatividade pode ser utilizada para facilitar a compreensão, reduzir a complexidade cognitiva e contribuir para apresentar informações úteis por meio de uma interface adequada.

Nesse sentido, o entendimento sobre interatividade possui grande importância para a construção de interfaces dos livros digitais interativos, pois, a comunicação entre o sujeito e o conteúdo ocorre mediante os recursos utilizados na interface.

Em ambientes digitais, a interatividade pode estar disponível em vários graus, desde a simples navegação pelo conteúdo de uma aplicação multimídia até a adaptação do conteúdo decorrente da interferência ativa do usuário. Assim, a presença da interatividade possibilita que o leitor possa receber respostas do sistema como resultado às suas ações (RIBEIRO, 2004).

Heikkilä (2012), contribui ao classificar a interatividade em quatro categorias, as quais diferenciam as possibilidades de atuação de acordo com finalidades específicas. $\mathrm{O}$ autor evidencia que a Interatividade Interfacial refere-se à composição da interface com suas funcionalidades de navegação e recursos disponíveis; já a Interatividade social oferece possibilidades de interação com outros usuários, como por exemplo, compartilhar informações a partir de recursos que o sistema disponibiliza; a Interatividade adaptiva, caracteriza-se pela personalização do conteúdo, adaptação de elementos e opções de controle que possibilite adequar a interface às necessidades do usuário; e, por fim, a Interatividade criativa refere-se à disponibilidade de recursos para modificar, editar, e criar conteúdos.

Nesse sentido, Santaella (2004) evidencia que quanto maior a interatividade disponível, maior será o potencial do sistema para que ocorra uma profunda experiência de imersão do leitor. Essa atividade mental se expressa na concentração, atenção, compreensão da informação e na interação contínua sobre os distintos estímulos apresentados.

Em vista disso, identificar os componentes da interatividade é essencial para analisar uma interface, como também, para projetar sistemas interativos. Assim sendo, Laurel (1991) apud Tori (2008) afirma que a interatividade de um sistema pode ser considerada como o somatório de três variáveis: frequência, abrangência e significância, que serão detalhadas a seguir:

- Frequência: corresponde aos momentos em que as interações estão disponíveis no conteúdo, ou seja, a periodicidade de ocorrência das oportunidades de interação inseridas em uma interface;

- Abrangência: refere-se aos recursos disponíveis, ou conjunto de opções oferecidas ao leitor no momento da interação. São as possibilidades de atuação sobre o conteúdo;

- Significância: é o componente subjetivo da interatividade, representa o quanto a atividade poderá ser importante para o leitor. Refere-se à escolha mais apropriada de 
apresentação dos conteúdos a fim de provocar significado.

Tori (2008), complementa que as variáveis de interatividade atuam em conjunto e, nesse processo, participam fatores objetivos e subjetivos. Durante a interação do leitor com o conteúdo, os fatores objetivos contribuem para que os fatores subjetivos se estabeleçam. O resultado entre esses dois polos representam a percepção que o usuário terá sobre o conteúdo da interface.

Assim, os fatores objetivos visam atender à maneira como os usuários lidam com a interatividade de uma interface. São atribuídos às qualidades que caracterizam o uso de um sistema, ou seja, a usabilidade. Em vista disso, é possível destacar que a usabilidade da interface busca garantir que as tarefas propostas possam ser concluídas com eficácia, eficiência e segurança. Além disso, o sistema deve ser projetado para atender, também, às necessidades psicológicas, cognitivas e emocionais do usuário, para tornar a interação uma experiência útil e agradável (ROGERS; SHARP; PREECE, 2013).

\section{Motivação por meio das Mídias}

O entendimento sobre os conceitos de interatividade permitem reconhecer alguns aspectos importantes que envolvem a interface e uso do livro digital interativo. Além de considerar essas abordagens em projetos, é pertinente também dedicar atenção aos aspectos subjetivos do comportamento dos leitores.

O fator emocional e afetivo que os produtos são capazes de comunicar precisam ser incluídos nas decisões e estratégias de design. Isso porque, um objeto estará sujeito à interpretação do usuário que o utiliza. Nesse processo de uso atuam os filtros fisiológicos (acuidade, percepção) e emocionais (atenção, motivação). Como resultado da percepção e julgamento que ocorra o usuário responde a esse produto (NIEMEYER, 2007; SAFER, 2007).

Norman (2008) afirma que as emoções participam e influenciam o processamento das informações pelo cérebro e determina três níveis para isso: o nível viceral, o nível comportamental e o reflexivo. No nível viceral, a informação é identificada como um primeiro contato que desencadeia julgamentos instantâneos. O nível comportamental referese ao controle das decisões voltadas à ação que resulta em um determinado tipo de comportamento. $\mathrm{O}$ nível reflexívo corresponde ao estágio do pensamento consciente, favorável ao raciocínio crítico e ao aprendizado.

Assim, as emoções influenciam os níveis de processamento, pois, a percepção sobre o que ébom ou perigoso impulsiona o indivíduo a modificar seu comportamento. Desse modo, o afeto negativo faz com que os processos mentais focalizam o problema, enquanto que, o afeto positivo amplia os processamentos mentais favorecendo a criatividade, a motivação e a aprendizagem de novas informações.

Nesse sentido, a motivação possui grande relevância, pois tem como significado a energia que mobiliza uma pessoa a agir. É uma atitude do indivíduo favorável às ações para superar ou alcançar objetivos. Desse modo, a motivação é a disposição que impulsiona a realização de tarefas na busca para atender necessidades importantes para o indivíduo (MINICUCCI, 1995 apud ALVES; BATTAIOLA, 2011).

A motivação pode ser de natureza intrínseca quando a atividade em si é estimulante induzindo o indivíduo a prosseguir em uma tarefa porque ela é inerentemente assimilada como agradável e prazerosa. Por outro lado, a motivação pode ser de natureza extrínseca quando procede do exterior da tarefa, ou seja, uma pessoa pode fazer algo não porque considerou a tarefa interessante, mas sim, porque fazê-la dará acesso a algo que deseje (CHISTENSEN, HORN, JOHNSON, 2012).

Por essa razão, Prevedello (2011) afirma que, quando as atividades presentes em uma interface forem percebidas pelo indivíduo como significativas, úteis e agradável existirá maior oportunidade para estabelecer a motivação intrínseca necessária para o aprendizado.

O uso de e-books por estudantes tem revelado uma melhoria nas práticas educativas dosalunos, segundo Marzano et al (2013), evidenciando que o e-book tem influencia positiva, sobretudo, por encorajar a interatividade entre o conteúdo e o leitor. Outro ponto destacado pelos autores foi que a motivação dos estudantes é ampliada com o uso de ebook, o que ocasiona retorno positivo em termos de qualidade de aprendizagem.

Os autores explicitam que a multimídia representa um potencial para compor conteúdos digitais. Concluem que a utilização do e-book gera interesse, pois, o envolvimento emocional é maior do que no material impresso, podendo oportunizar uma aprendizagem ativa e flexibilizar os conteúdos com o uso de diferentes mídias.

Nesse sentido, o livro digital interativo, por viabilizar a integração de recursos multimídia ao conteúdo, torna-se uma publicação capaz de instigar o leitor apresentandolhe atividades e desafios semelhante aos jogos. Por meio da participação do leitor com o conteúdo apresentado poderá despertar a atenção, a motivação, proporcionar envolvimento físico e uma imersão mais profunda com as informações contidas no livro digital (TEIXEIRA, GONÇALVES, 2013).

Ribeiro (2004) comenta que o uso das mídias, como o texto, áudio, vídeo, animação e imagem presente no livro digital interativo, é essencial para tornar a composição dinâmica. $\mathrm{O}$ autor pontua que o texto é considerado um meio dominante para apresentação de informações convencionais ou multimídia, contudo, as representadas textuais devem estar adequadas ao tipo de aplicação, como também, à necessidades dos usuários.

O áudio possui potencial para despertar reações emocionais rapidamente. Pode ser empregado com finalidade de orientação, como sinais para a percepção sobre algum acontecimento, ou ainda, ser utilizado como efeitos sonoros. A informação sonora também possui influência sobre como o usuário irá lembrar da interface (SCHUYTEMA, 2008).

Alves (2012), em seus estudos, afirma que as animações, ou representações animadas, estiveram amplamente associadas ao entretenimento. $\mathrm{O}$ uso de animações em objetos de 
aprendizagem precisam considerar sobretudo a informação de modo que, seja de fácil compreensão para que o usuário possa obter benefícios desse recurso.

O vídeo é uma mídia que permite a visualização das informações em um determinado período temporal. Tem como característica apresentar as informações de modo sequencial. Por essa razão é preciso considerar a duração mais apropriada ao interesse do usuário (PORTUGAL, 2013).

As imagens possuem o potencial de representar informações com maior facilidade, são também facilmente reconhecidas e lembradas. Alguns conteúdos são melhores assimilados por meio de imagens do que somente por texto (LIDWELL, HOLDEN, BUTLER, 2010).

Para que o conteúdo multimídia e interativo presente no livro digital seja adequado e possa estimular a motivação do leitor é preciso, além de compreender as características das diferentes mídias, observar recomendações que orientem o uso das mídias interativas inseridas em um conteúdo.

Desse modo, os autores Alves e Battaiola (2011) elencaram recomendações para promover a motivação em objetos educacionais. Tais critérios foram estruturados pelos autores após estudo e compilação de duas teorias: teoria de fluxo, do autor Csikszentmihalyi (1990) que identifica princípios para a experiência do envolvimento máximo com uma tarefa, e a teoria de Taxonomia de Malone e Lepper (1987) que propõem heurísticas para o design de jogos.

Assim, as recomendações, que serão apresentadas a seguir, podem servir para orientar o desenvolvimento e análise de interfaces digitais interativas como o livro digital.

1. Inserção de desafios: a construção da informação com elementos que representem desafios podem favorecer maior engajamento na realização da atividade. Porém, deve-se observar que o desafio oferecido seja equivalente às habilidades do usuário, caso contrário, a tarefa pode provocar desinteresse;

2. Objetivos claros: a motivação se estabelece quando existe a necessidade de atingir metas. Objetivos claros são essenciais para manter o interesse do usuário na continuidade e conclusão da tarefa. Os objetivos podem ser apresentado por meio de um sistema de regras, instruções e sinalizações que evidenciem o que deve ser realizado;

3. Feedback das ações: feedback das ações proporciona segurança oferecendo condições adequadas para a execução das atividades. $O$ feedback deve responder às ações do usuário e guiá-lo de modo confortável pela interface.

4. Apelo emocional: a inserção de narrativas, personagens e personalização da informação podem auxiliar a manter o interesse e engajamento na tarefa. Uma narrativa com apelo visual tem a finalidade de envolver o usuário, como também, favorecer a identificação com seu repertório;

5. Processamento cognitivo: refere-se ao uso de metáforas, analogias e exemplos que possam auxiliar no processamento da informação, facilitando conexões com conhecimento já adquiridos. $\mathrm{O}$ uso de recursos gráficos e elementos visuais conhecidos podem favorecer a assimilação das informações;

6. Curiosidade sensorial: Está relacionado à percepção estética e visual que pode ser aplicada ao se escolher uma linguagem gráfica com que a informação será apresentada. O padrão estético pode ser uma forma de atrair e motivar o usuário a interagir com a interface do sistema;

7. Controle sobre a atividade: permite o controle, domínio e sobre as ações enquanto realiza a atividade. O controle sobre os recursos melhora a interação com a interface e ampliam a motivação. A possibilidade de controle da situação pode significar melhor entendimento sobre o conteúdo e melhorar a adequação do tempo às necessidades do usuário;

8. Imersão: refere-se ao estado de concentração na atividade vivenciada e transformação da sensação de tempo que pressupõem engajamento, interesse e atenção, focados em um objetivo. Esses estados seriam o resultado da inserção dos parâmetros já citados.

\section{Procedimentos Metodológicos}

Após o levantamento bibliográfico, um livro digital foi selecionado para a análise descritiva a fim de demonstrar, por meio de um exemplo, os componentes da interatividade que podem promover a motivação. Para tanto, uma ampla pesquisa de livros digitais foi feita no sistema iTunes. Assim, a etapa posterior à da coleta de materiais foi a escolha de um exemplar para a análise detalhada.

A análise descritiva foi realizada seguindo como parâmetro as recomendações propostas por Alvese Battaiola (2011) para promover a motivação em objetos educacionais; e os componentes da interatividade apresentados por Laurel (1991) apud Tori (2008).

\section{Apresentação do Objeto de Estudo}

Para a análise descritiva, o livro digital selecionado foi o WWF Together, distribuído pelo WORLD WILDLIFE FUND, organização sem fim lucrativo. A primeira versão do livro digital foi publicada no ano de 2012 e a última atualização foi feita em 2014. Disponível de forma gratuita, o book app pertence à categoria "educação". Sua configuração exige compatibilidade com iOS 6.0 ou posterior, apena com leitura pelo iPad. O livro digital WWF Together foi escolhido por apresentar em seu conteúdo diversas aplicações de recursos multimídia e interativos.

O acesso ao conteúdo do livro ocorre a partir do ícone que fica disponível na tela do dispositivo. Ao tocar no ícone inicia-se uma abertura em forma de animação com o áudio ao fundo. A animação demonstra o processo de dobradura em papel, simulando a técnica de origami, que resulta na figura de um urso panda. Essa linguagem de dobradura é utilizada e mantida como estética do livro. 

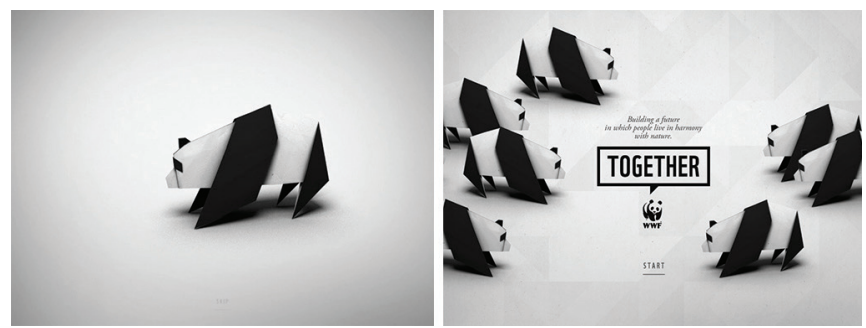

Figura 1: capa e abertura do livro.

\section{Resultados}

A análise segundo os requisitos de Alves e Battaiola (2011) para promover a motivação em objetos educacionais demonstraram os seguintes resultados:

1. Inserção de desafios: alguns conteúdos instigam a participação do leitor, por meio de comandos na superfície da tela ou movimentos com o dispositivo. Desse modo, as informações são reveladas após a interação o que pode favorecer o envolvimento e estimular a curiosidade.
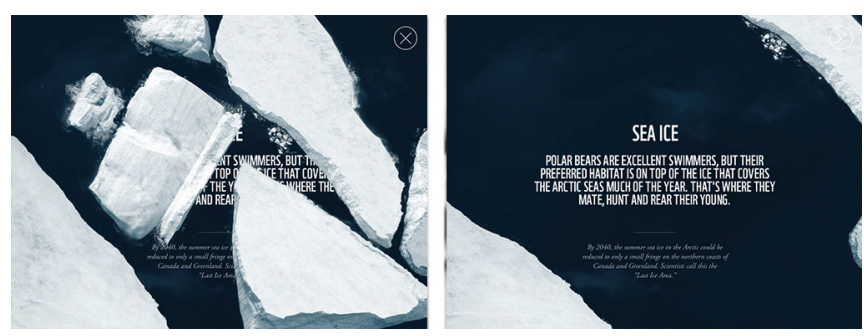

Figura 2: mover os blocos de gelo para ler o texto.

2. Objetivos claros: As instruções e orientações disponíveis são adequadas para que o leitor compreenda o que deve fazer, como seguir a leitura dentro de uma seção específica, assim como, usar as funcionalidades do livro como um todo;
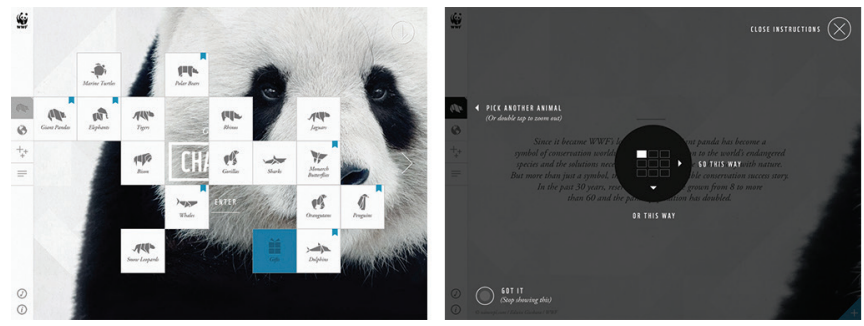

Figura 3: sumário e instruções.

3. Feedback das ações: o feedback das ações são evidentes e relevantes para a orientar a continuidade das atividade.
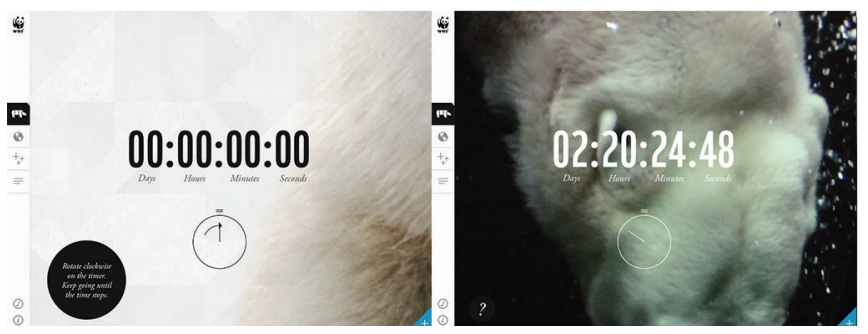

Figura 4: interação cronometro.

4. Apelo emocional: o apelo emocional expressa-se na forma como as fotografias são usadas. Além disso, para cada animal é atribuída uma palavra que resalta uma qualidade de sua personalidade. $O$ apelo emocional também pode ser exemplificado pela possibilidade do leitor poder construir os personagens com dobradura em papel. Assim, o apelo emocional é um critério muito usado, sobretudo, no intuito de estimular o cuidado e preservação dos animais, objetivo central da obra.
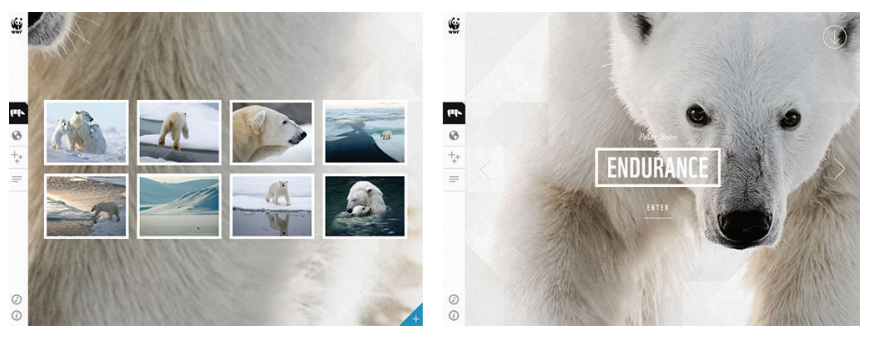

Figura 5: galeria de fotos.

5. Processamento cognitivo: considera-se que o uso do globo interativo, o qual permite visualizar a ocorrência das espécies no espaço mundial, um recurso que facilita o

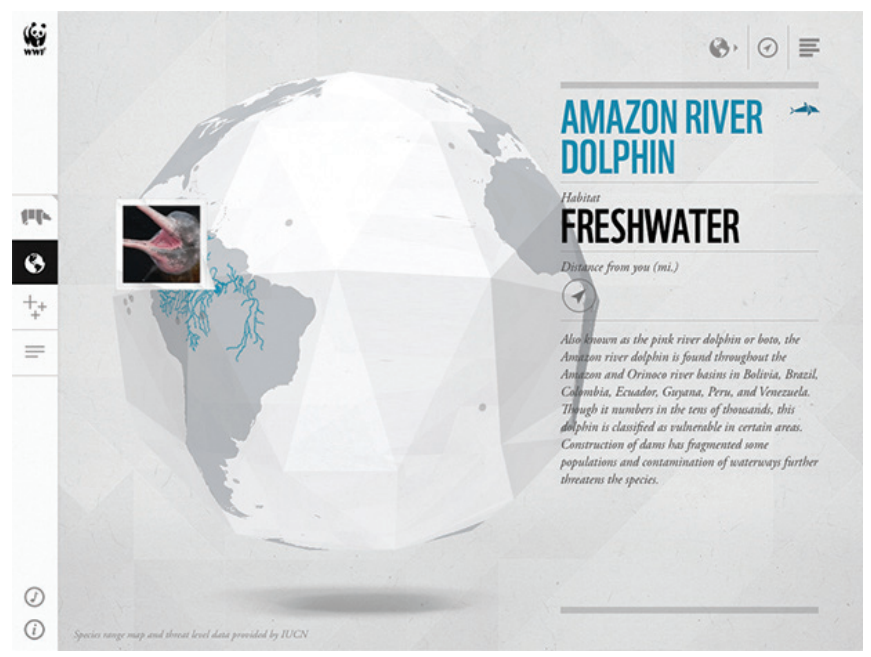

Figura 6: globo interativo. 
processamento cognitivo;

6. Curiosidade sensorial: a curiosidade sensorial atribuída à percepção visual e estética, foi identificada como o uso linguagem de dobradura de papel, uso das fotografias valorizadas com tamanhos expressivos na tela;
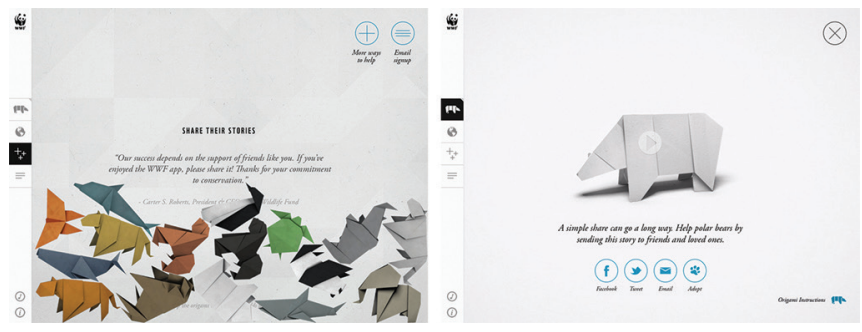

Figura 7: recursos para a técnica de dobradura em papel.

7. Controle sobre a atividade: de modo geral, as atividades oferecem controle ao usuário. Contudo, os vídeos não disponibilizam a opção para visualizar a duração;
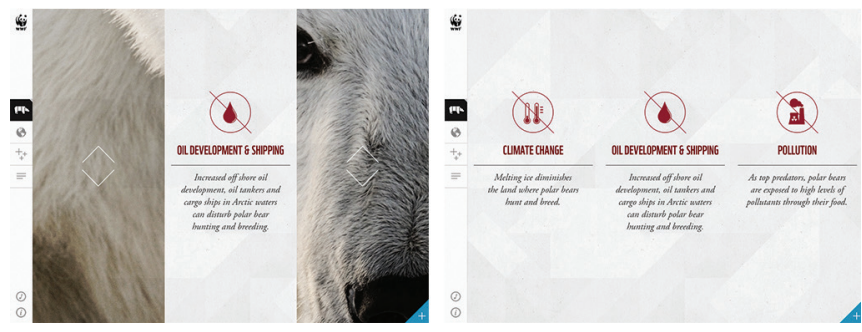

8. Imersão: A imersão ocorre em interações em que o leitor sente interesse inicial e permanece motivado até a conclusão da atividade. Assim como o processamento cognitivo, são critérios mais subjetivos característicos de cada indivíduo.

Em seguida serão apresentados os resultados da análise feita a partir dos componentes da interatividade: frequência, abrangência e significaria, propostos por Laurel (1991) apud Tori (2008).

Frequência: a frequência, caracteriza-se pelas oportunidades de interação oferecidas ao usuário. No livro foi percebida uma alta frequência, pois dentro de cada seção apenas a página introdutória não disponibiliza recurso interativo, sendo a informação apresentada por um texto. Portanto, quase todas as telas, ou páginas do livro, possuem algum tipo de interatividade.

Uma vez que a abrangência e a significância estão associadas ao momento da interação serão descritas no quadro a seguir:

\begin{tabular}{|c|c|c|}
\hline Interatividade & Abrangência & Significância \\
\hline $\begin{array}{l}\text { Mover os blocos de } \\
\text { gelo. } \\
\text { (figura 2) }\end{array}$ & $\begin{array}{l}\text { Deslizar o dedo } \\
\text { sobre a tela, } \\
\text { movendo os blocos } \\
\text { de gelo para poder } \\
\text { visualizar o texto } \\
\text { que se encontra por } \\
\text { baixo. }\end{array}$ & $\begin{array}{l}\text { Deslizar o dedo } \\
\text { sobre a tela, } \\
\text { movendo os blocos } \\
\text { de gelo para poder } \\
\text { visualizar o texto } \\
\text { que se encontra por } \\
\text { baixo. }\end{array}$ \\
\hline $\begin{array}{l}\text { Interação } \\
\text { cronometro. (figura } \\
\text { 4) }\end{array}$ & $\begin{array}{l}\text { Permite controlar } \\
\text { o progresso em um } \\
\text { cronometro. }\end{array}$ & $\begin{array}{l}\text { Essa interação é útil } \\
\text { para fazer o leitor } \\
\text { sentir e visualizar a } \\
\text { passagem de tempo. }\end{array}$ \\
\hline $\begin{array}{l}\text { Galeria de fotos. } \\
\text { (figura 5) }\end{array}$ & $\begin{array}{l}\text { Ampliar fotografia } \\
\text { e visualizar } \\
\text { informações. }\end{array}$ & $\begin{array}{l}\text { Recursos utilizados } \\
\text { para valorização } \\
\text { da imagem com } \\
\text { possibilidade de } \\
\text { relacioná-la à uma } \\
\text { explicação textual. }\end{array}$ \\
\hline $\begin{array}{l}\text { Interação sobre } \\
\text { imagem (figura 8) }\end{array}$ & $\begin{array}{l}\text { Mover partes da } \\
\text { imagem para ver } \\
\text { informações. }\end{array}$ & $\begin{array}{l}\text { Possui pouca } \\
\text { relevância para a } \\
\text { informação, mas } \\
\text { permite que a } \\
\text { imagem do fundo } \\
\text { seja visível. }\end{array}$ \\
\hline $\begin{array}{l}\text { Recursos para } \\
\text { a técnica de } \\
\text { dobradura em papel } \\
\text { (figura 7) }\end{array}$ & $\begin{array}{l}\text { Vídeo que pode } \\
\text { ser compartilhado } \\
\text { nas redes sociais. } \\
\text { Tutorial que pode } \\
\text { ser impresso. }\end{array}$ & $\begin{array}{l}\text { As opções são } \\
\text { adequadas e } \\
\text { convidativas à } \\
\text { participação do } \\
\text { usuário com o } \\
\text { conteúdo. }\end{array}$ \\
\hline
\end{tabular}

Quadro 1: Resultado da análise sobre os componentes abrangência e significância.

\section{Discussões}

Após as análises, foi possível verificar que os componentes da interatividade: frequência, abrangência e significância, de Laurel (1991) apud Tori (2008) foram úteis para identificar como a interatividade foi empregada no livro digital e se as escolhas feitas para representar os conteúdos colaboravam, de forma significativa, para potencializar a expressão das informações abordadas.

As recomendações de Alves e Battaiola (2011) utilizadas foram úteis para avaliar a interface do livro digital interativo, contudo alguns critérios foram mais expressivos que outros. 
Também foi possível observar que critérios semelhantes poderiam ser reduzidos para não tornar a análise repetitiva. $O$ quadro abaixo visa simplificar as recomendações agrupando por semelhanças.

\begin{tabular}{|l|l|}
\hline $\begin{array}{l}\text { Inserção de desafios; Objetivos } \\
\text { claros; Feedback das ações e, } \\
\text { Controle sobre a atividade. }\end{array}$ & $\begin{array}{l}\text { Apelo emocional; Curiosidade } \\
\text { sensorial; Processamento } \\
\text { cognitivo; Imersão }\end{array}$ \\
\hline Frequência e abrangência. & Significância. \\
\hline
\end{tabular}

Quadro 2: síntese adaptada de Alves e Battaiola (2011) e Laurel (1991) apud Tori (2008).

\section{Conclusão}

A partir da popularização dos dispositivos digitais, os livros passaram a ser publicados também em formato eletrônico. Assim, foi possível integrar ao conteúdo recursos multimídia e interativos para representar informações.

Este estudo buscou compreender aspectos da interatividade, presente nas interfaces digitais, e da motivação do leitor. Para isso, este artigo, desenvolveu uma análise sobe um livro digital escolhido, utilizando como método os requisitos para promover a motivação em objetos educacionais de Alves e Battaiola (2011), assim como, os componentes da interatividade Laurel (1991) apud Tori (2008).

Após a análise, foi possível concluir que a representação dos conteúdos, utilizando recursos interativos e multimídia, no livro digital deve ter o propósito de facilitar a compreensão e promover a motivação do leitor. Para isso, é preciso que as diferentes formas de abordar as mídias interativas tenham significância e apresentem coerência com a informação.

Quantoà interatividade presente no livro digital analisado, a frequência e a abrangência instigam o leitor oferecendo oportunidade de participação com os elementos da interface. Nesse processo, inserção de desafios; objetivos claros; feedback das ações e, controle sobre a atividade, são indispensáveis. A significância, enquanto caráter subjetivo da interatividade, está relacionada principalmente ao apelo emocional; curiosidade sensorial; processamento cognitivo e Imersão.

A composição do livro com diferentes abordagens ao longo das páginas, demonstrou que a interatividade pode estimular a curiosidade e a motivação, pois, a expectativa gerada pode incentivar a leitura por todo o livro.

\section{References}

ALVES, M.; BATTAIOLA, A. (2011). Recomendações para ampliar motivação em jogos e animações educacionais. In: simpósio brasileiro de games e entretenimento digital , 10., Salvador. Anais... Disponível em:<http://www.humanas.ufpr. br/portal/ ppgdesign/files/2013/07/Alves-Battaiola-2011.pdf >. Acesso em: mai 2015.

ALVES, Marcia Maria. (2012). Design de animações educacionais: Recomendações de conteúdo, apresentação gráfica e motivação para aprendizagem. 2012. 240 f. Dissertação (Mestrado) - Curso de Programa de Pós-graduação em Design, Setor de Ciências Humanas, Letras e Artes, Universidade Federal do Paraná., Curitiba, 2012.

BONSIEPE, Gui.(2011). Design, cultura e sociedade. São Paulo: Blucher.

CHISTENSEN; HORN; JOHNSON. (2012). Inovação na sala de aula: como a inovação disruptiva muda a forma de aprender. Porto Alegre: Bookman.

COELHO, L. A. L. (Org). (2008). Conceitos-chave em design. Rio de Janeiro: Ed. PUC-Rio; Novas Ideias.

HASLAM, A. (2010). O livro e o designer II: como criar e produzir livros. São Paulo: Rosari.

HEIKKILÄ,H.(2012). Interactivity in new publishing platforms. Disponível em < http://virtual.vtt.fi/virtual/nextmedia/ Deliverables-2012/D1.1.1.5_eReading_Interactivity\%20 in\%20new\%20publishing\%20platforms.pdf>. Acesso em: maio 2012.

LÉVY, P. (1993) As tecnologias da inteligência: O futuro do Pensamento na Era da Informática. Rio de Janeiro: Editora 34. LIDWELL, W.; HOLDEN, K.; BUTLER, J. (2010) Princípios universais do design. Porto Alegre: Bookman.

MARZANO, A.; TAMMARO, R.; NOTTI, A. M.; D'ALESSIO, A.; ESTASIO, D. (2013). The use of e-books in education to improve learning. In: INTERNATIONAL CONFERENCE ON EDUCATION AND NEW LEARNING TECHNOLOGIES, 5., 2013. Barcelona, Spain: Edulearn13 Proceedings, 2013. 7 p.

NIEMEYER, Lucy. (2007). Elementos de Semiótica aplicados ao Design. Rio de Janeiro: 2AB.

NORMAN, D. (2008). Design emocional: Por que adoramos (ou detestamos) os objetos do dia-a-dia. Rio de janeiro: Rocco.

PINSKY, L.. (2013). Do papel ao digital: como as novas tecnologias desafiam a função do editor de livros de história. Dissertação (Mestrado) Escola de Comunicação e Artes, Universidade de São Paulo, São Paulo.

PORTUGAL, C. (2013). Design, Educação e Tecnologia. Rio de Janeiro: Rio Books.

ROGERS, Y.; SHARP,H.; PREECE, J. (2013). Design de Interação: além da interação homem-computador. Porto Alegre: Bookman.

PREVEDELLO, C. (2011). Design de interação e motivação nos projetos de interface para objetos de aprendizagem para EAD. Dissertação (Mestrado) - Programa de Pós-Graduação em Design - Universidade Federal do Rio Grande do Sul. Porto Alegre.

SCHUYTEMA, P. (2008). Design de games: uma abordagem prática. São Paulo: Cengage Learning.

PRIMO. A.; CASSOL. M. (1999). Explorando o conceito de interatividade: definições e taxonomias. In. Informática na educação: teoria \& prática. V.2 n. 2.

PROCÓPIO, E. (2010). O livro na era digital: o mercado editorial e as mídias digitais. São Paulo: Giz Editorial.

QUEIROZ, S. G.; CARDOSO, C. L.; GONTIJO, L. A. (2009). Design Emocional e Semiótica: caminhos para obter respostas emocionais dos usuários. In. Estudos em Design, Rio de Janeiro, 
v.17.1. 2009. Disponível em <http://www.maxwell.lambda. ele.puc-rio.br/estudos_em_design. php?strSecao=INPUT> Acesso em: mai 2015.

RIBEIRO, Nuno M. (2004). Multimédia e Tecnologias Interactivas, FCA - Editora de Informática.

SAFFER, D. (2007) Designing for Interaction: Creating Smart Applications and Clever Devices. Berkeley, CA: New Riders.

SANTAELLA, L. (2004). Navegar no ciberespaço: o perfil cognitivo do leitor imersivo. São Paulo: Paulus.

TEIXEIRA, D. J.; GONÇALVES, B.S. (2013). Digital Children's Books: An Analysis of the eBook-app, The Numberlys from the Perspective of Game Design. In: Senses \& Sensibility in Florianópolis: Advertising, Design, Fashion, Marketing,
Photography and Visual Culture in the Right Place. Proceedings book of the UNIDCOM/IADE's 7th International Conferece. Florianópolis, 2013. p. 62 - p. 71.

TORI, (2008). Romero. Games e interatividade. Em busca da felicidade. In: SANTAELLA, L; ARANTES, P. (Orgs.). Estéticas tecnológicas: Novos modos de sentir. São Paulo: Educ, p. 439450.

UNGARETTI, C. E.; FRAGOSO, S. (2012). Design gráfico para e-books e livros impressos: proposta de método de projeto simultâneo para explorar a complementaridade dos suportes. In: Educação Gráfica, Bauru, v.16, n. 3. 